\title{
PENGEMBANGAN BUDIDAYA STROBERI BERBASIS BARCODE YANG MEMUAT LINK TUTORIAL BUDIDAYA GUNA MENINGKATKAN PARIWISATA DESA
}

\author{
Helmi Wicaksosno ${ }^{1}$, Lutfi Anggraeni ${ }^{2}$, Rudyansah Galang Rahadi ${ }^{1}$, Dicky Dryan \\ Agassi $^{3}$, Rizkiati Silvany Umarella ${ }^{3}$, Mohamad Yandi Akbar ${ }^{2}$, Jiescodala Jumadi ${ }^{3}$, \\ Winda Martha Sari², Dewi Anissulalah ${ }^{3}$, Lucky Dea Safrina ${ }^{1}$, Arul Dicky Permana ${ }^{2}$ \\ ${ }^{1}$ Fakultas Keguruan dan Ilmu Pendidikan, Universitas Islam Malang \\ ${ }^{2}$ Fakultas Ekonomi dan Bisnis, Universitas Islam Malang \\ ${ }^{3}$ Fakultas Teknik, Universitas Islam Malang \\ Korespondensi email: social_poemz@yahoo.com
}

\begin{abstract}
ABSTRAK
Stroberi (Strawberry sp.) merupakan salah satu komoditas unggulan dari Kelompok Tani Desa Tamankuncaran. Dengan produktivitas dan mutu stroberi yang baik dari Kelompok Tani Desa Tamankuncaran, maka hal tersebut menjadi potensi dalam meningkatkan Pariwisata dan perekonomian Desa. Produktivitas stroberi yang baik dapat dihasilkan dengan memperhatikan cara penanaman dan perawatan stroberi yang baik. Pemanfaatan teknlogi barcode adalah salah satu penunjang untuk mempermudah penyampaian informasi kepada seluruh warga desa yang ada tanpa mencetak banyak kertas. Pemanfaatan barcode ini juga akan menuntut masyarakat desa untuk membuka mata akan berkembangnya teknologi. Penggunaan barcode ini juga sangat mudah dan murah tidak menghabiskan banyak biaya hanya memerlukan perangkat android yang mayoritas setiap warga desa memiliki perangkat tersebut. Sosialisasi tentang barcode ini akan menunjang proses pengenalan barcode kepada masyarakat desa yang mayoritas masih belum mengerti. Penggunaan barcode ini juga akan menunjang hal lain diluar program kerja ini setelah warga mengetahui proses penggunaan barcode ini warga akan dengan mudah memanfaatkan barcode ini untuk menyimpan banyak informasi yang bermanfaat.
\end{abstract}

Kata Kunci: stroberi; perawatan pertanian.

\section{PENDAHULUAN}

Stroberi (Strawberry sp.) merupakan buah yang mudah tumbuh di daerah beriklim subtropis. Namun seiring dengan perkembangan teknologi, pengembangan Stroberi (Fragaria sp.) merupakan salah satu komoditas buah-buahan yang penting didunia, terutama untuk negara-negara beriklim subtropics (W. K. Manurung \& Suminarti, 2019). Seiring perkembangan ilmu dan teknologi pertanian yang semakin maju, kini stroberi mendapat perhatian pengembangannya di daerah beriklim tropis. Di Indonesia, walaupun stroberi bukan merupakan tanaman asli Indonesia, namun pengembangan komoditas ini yang berpola agribisnis dan agroindustry dapat dikategorikan sebagai salah satu sumber pendapatan dalam sektor pertanian. Stroberi ternyata dapat tumbuh dan berproduksi dengan baik dalam kondisi iklim seperti di Indonesia (Saroinsong et al., 2012) (Mappanganro, 2013).

Stroberi merupakan salah satu jenis buah-buahan yang memiliki nilai ekonomi yang tinggi dan mempunyai banyak manfaat. Bagian yang dapat dimakan dari buah stroberi 
mencapai 96\% (Y. D. Manurung et al., 2015) (Driyunitha \& Pasapan, 2016). Stroberi tidak hanya dikonsumsi dalam keadaan segar tetapi dapat diolah menjadi selai, sirop, dodol, manisan, jus, yoghurt, kue, dan bahan baku pembantu pembuat es krim. Kandungan gizinya tinggi dan komposisi gizinya cukup lengkap. Selain mengandung berbagai vitamin dan mineral (Megasari, 2019), buah stroberi terutama biji dan daunnya diketahui mengandung ellagic acid yang berpotensi sebagai penghambat kanker, mempercantik kulit, menjadikan gigi putih, menghilangkan bau mulut serta meningkatkan kekuatan otak dan penglihatan. Akar stroberi mengandung zat anti radang (Rofatin et al., 2016) (Hakim, 2015).

Selama ini salah satu usaha yang dilakukan petani untuk meningkatkan produksi tanaman stroberi adalah dengan penggunaan pupuk anorganik. Penggunaan pupuk anorganik menjadi hal yang sulit dipisahkan dalam kegiatan budidaya tanaman stroberi. Dampak dari penggunaan pupuk anorganik memang menghasilkan peningkatan produktivitas tanaman yang cukup tinggi (Alawy \& Pujiwati, 2018), namun penggunaan pupuk anorganik dalam jangka yang relatif lama umumnya berakibat buruk, meninggalkan residu pada produksi tanaman, dan tidak ramah lingkungan. Penggunaan pupuk kandang atau kompos selama ini diyakini dapat mengatasi permasalahan yang ditimbulkan oleh pupuk anorganik. Akan tetapi pupuk kandang atau kompos yang berbentuk padat juga memiliki kekurangan, antara lain dalam hal transportasi, perhitungan dosis kurang tepat, dan respon tanaman lebih lambat (Sholihah \& Nurhidayati, 2018). Untuk mengatasi hal tersebut maka kotoran ternak dapat diolah menjadi pupuk organik sehingga dapat efisien dalam hal tenaga kerja, biaya, dan konsentrasi yang diberikan sesuai dengan yang dibutuhkan tanaman. Kotoran ternak yang dapat digunakan seperti kotoran sapi, kambing, kelinci, ayam atau ternak lainnya. Selain dari kotoran padat hewan ternak, urine hewan ternak juga dapat dimanfaatkan.

Dalam pembudidayaan stroberi oleh masyarakat di desa Tamankuncaran, masih banyak warga yang kurang memahami cara membudiyakan stroberi dengan benar. Kurang nya pengetahuan akan pembudidayaan stroberi menyebabkan mereka sering gagal panen. Dengan kurangnya pengetahuan tersebut, mereka berpikir bahwa membudidayakan stroberi sangatlah sulit. Pada dasarnya jika warga diberikan pengarahan dan penyuluhan bagaimana membudidayakan stroberi dengan baik, hasil yang diperoleh dari pembudidayaan stoberi ini sangatlah memberikan manfaat yang akan membantu perekonomian masyarakat di Desa Tamankuncaran. Dengan adanya peluang yang menjanjikan tersebut, maka dari itu KKN PPM Tematik Universitas Islam Malang kelompok 54 mempunyai sebuah program kerja yaitu membuat barcode, yang akan mempermudah masyarakat untuk mengetahui cara membudidayakan strobery di desa Tamankuncaran, Kec. Tirtoyudo, Kab. Malang.

\section{METODE}

Metode pelaksaanan yang dilakukan pada saat observasi lapang meliputi (1) Observasi pengguna smartphone yang ada di desa dan mencari informasi, (2) Meminta izin kepada Kepala Desa dan Ketua Kelompok Tani untuk melaksanakn program kerja pokok yang sudah direncanakan kelompok 54, (3) Melaksanakan wawancara dan perekaman video, (4) Proses editing dan design, (5) Sosialisasi penggunaan barcode yang dilakukan didesa Tamankuncaran, Kecamatan Tirtoyudo, Kabupaten Malang.

Kegiatan dilaksanakan di salah satu lahan kelompok tani Tamankuncaran yang terletak di Lingkungan Kelurahan Tamankuncaran, Kecamatan Tirtoyudo Kabupaten Malang Provinsi Jawa Timur, dengan ketinggian tempat $1575 \mathrm{~m}$ dpl dan temperatur ratarata berkisar 18 - 27 oC. Berlangsung mulai 01 Februari 2020 hingga 01 Maret 2020. 
Bahan-bahan yang digunakan dalam percobaan ini adalah bibit stroberi varietas Rosalinda sweet chalie, media tanah, sekam, polibag ukuran $50 \times 50 \mathrm{~cm}$ dan $20 \times 18 \mathrm{~cm}$, air. Alat-alat yang digunakan dalam percobaan ini berupa ember plastik, tapisan, gelas ukur, alat pengaduk, sekop, gunting, dan alat tulis-menulis.

\section{HASIL DAN PEMBAHASAN}

Penulis telah memperoleh beberapa temuan dan informasi tentang buah stroberi. Diantaranya informasi yang kami peroleh dari bapak Wagiyo ketua kelompok tani desa Tamankuncaran, kecamatan Tirtoyudo kabupaten Malang bahwasannya desa Tamankuncaran ini sangat berpotensi menjadi desa pariwisata terutama menjadi kampung stroberi. Namun sayangnya warga belum banyak yang tahu cara membudidayakan dan cara perawatan stroberi dengan benar. Oleh karena itu dengan adanya kegiatan ini diharapkan dapat membantu menginformasikan dalam membudidayakan tanaman stroberi dan perawatan stroberi.

Dalam upaya untuk meningkatkan produktivitas dan kualitas tanaman stroberi, ada dua poin yang perlu dilakukan (1) pembudidayaaan dan (2) perawatan stroberi.

\section{Pembudidayaan Tanaman Strawberry}

a. Siapkan strawberry induk

Agar strawberry pertumbuhannya cepat, maka tidak digunakan bibit tumbuhan strawberry untuk budidaya, melainkan induk strawberry yang dapat menghasilkan anakan.

b. Menakar pupuk

Sangat penting penakaran pupuk untuk perkembangbiakan strawberry. Dalam hal ini perbandingan pupuk dengan tanah yaitu 1:2. Pupuk yang biasanya digunakan yaitu pupuk kimia sesuai kebutuhan. Takaran tersebut dimaksudkan agar memaksimalkan pertumbuhan strawberry. Setelah dicampur masukkan ke polybag.

c. Cari cabang anak induk strawberry yang menjulur

Ada beberapa cabang anak induk strawberry yang akan menjalar, pilihlah cabang yang paling bagus untuk ditanamkan ke polybag selanjutnya. Cabang induk yang bagus biasanya memiliki diameter yang besar dengan warna yang segar.

d. Penanaman cabang anak induk

Tempatkan cabang anak induk ke polybag yang telah disiapkan dan tempatkan disamping polybag induk. Setelah itu, tunggu beberapa hari sampai anak induk tumbuh akar dan menjadi induk baru (biasanya satu sampai dua minggu).

e. Potong induk baru tersebut dari induk yang lama

Setelah induk yang baru cukup kuat dan mulai tumbuh 3 sampai 5 daun, maka cabang dari induk yang lama sudah bisa dipotong.

\section{Cara merawat Strawbery}

a. Membersihkan rumput dan daun yang kering ditanaman Strawbery.

b. Pada musim kemarau, strawberry di siram sehari satu kali (pada pagi atau sore hari). Untuk takaran air kurang lebih $1 / 2$ liter per polybag.

c. Pemberian pupuk kimia (npk mutiara atau npk phonska) dengan takaran $100 \mathrm{gr}$ pupuk dan 20 liter air. (Per polybag $120 \mathrm{ml}$ ).

d. Mengecek tanaman seminggu sekali untuk pertumbuhannya yang bagus.

Akhirnya setelah kami melakukan Analisis, penulis berinisiatif untuk melaksanakan sebuah Program Kerja pengembangan budidaya stroberi berbasis barcode dengan memuat linktutorial budidaya. Progam ini bertujuan untuk mempermudah masyarakat desa mempelajari bagaimana cara membudidayakan tanaman stroberi dengan baik, sehingga kedepannya dapat menunjang progam pariwisata stroberi di desa tamankuncaran. 


\section{KESIMPULAN}

Berdasarkan hasil dari observasi lapangan yang telah kami lakukan di Dusun Krajan yang merupkan bagian dari Desa Tamankuncaran, dapat disimpulkan bahwa pembudidayaan tanaman stroberi haruslah tepat dan benar. Walaupun bisa dikatakan mudah, ada beberapa hal yang harus diperhatikan dalam penanganan tanaman stroberi. Untuk itu, kami memiliki salah satu ide pemanfaatan teknologi informasi untuk membantu warga desa tamankuncaran yaitu dengan media "QR code" Setelah adanya sosialisasi mengenai QR Code sebagai media untuk mempermudah penyebaran informasi budidaya stroberi tersebut meningkatkan antusias masyarakat Desa Tamankuncaran. Dan hal tersebut akhirnya berdampak baik pada peningkatan produktivitas dan mutu stroberi di Desa Tamankuncaran.

\section{UCAPAN TERIMA KASIH}

Dalam penyusunan artikel ini kami banyak mendapat saran, dorongan, bimbingan serta keterangan-keterangan dari berbagai pihak yang merupakan pengalaman yang tidak dapat diukur secara materi, namun dapat membukakan mata kami bahwa sesungguhnya pengalaman dan pengetahuan tersebut adalah guru yang terbaik bagi kami. Oleh karena itu dengan segala hormat dan kerendahan hati perkenankanlah kami mengucapkan terima kasih kepada:

1. Bapak Prof. Dr. H. Maskuri, M.Si selaku rektor Universitas Islam Malang

2. Ibu Dr. Nour Athiroh Abdoes Sjakoer, S. Si., m.Kes., selaku ketua LPPM UNISMA

3. Bapak Helmi wicaksono, M.Pd selaku DPL KKN di desa Tamankuncaran yang memberikan pengarahan dan motivasi sebelum dan selama KKN.

4. Bapak Untung Slamet selaku Kepala Desa di desa TamanKuncaran yang telah membingbing dan membantu untuk mengsukseskan program kerja yang kami lakukan di desa tamankuncaran.

5. Bapak Wagiyo selaku narasumberdi desa Tamankuncaranyang telah memberikan informasi dengan lengkap dan mempermudah kami dalam penyelesaian program kerja kelompok 54.

6. Dan seluruh pihak yang terlibat yang tidak dapat kami sebutkan satu persatu.

Dalam penyusunan artikel ini, kami menyadari masih terdapat banyak kekurangan yang dibuat baik sengaja maupun tidak sengaja, dikarenakan keterbatasan ilmu pengetahuan dan wawasan serta pengalaman yang kami miliki. Untuk itu penulis mohon maaf atas segala kekurangan tersebut tidak menutup diri terhadap segala saran dan kritik serta masukan yang bersifat kontruktif bagi kami. Akhir kata semoga dapat bermanfaat bagi penulis maupun masyarakat luas

\section{DAFTAR RUJUKAN}

Alawy, T., \& Pujiwati, I. (2018). Pengembangan Biogas Kotoran Sapi di Kel. Kedopok Kec. Kedopok Probolinggo. Jurnal Inovasi Hasil Pengabdian Masyarakat (JIPEMAS), 1(1), 21-24. https://doi.org/10.33474/jipemas.v1i1.1475

Driyunitha, \& Pasapan, L. (2016). Pengaruh Pemberian Berbagai Konsentrasi Pupuk Cair Bioboost terhadap Pertumbuhan Tanaman Strawberry (Fragaria sp.). Jurnal Ilmiah AgroSaint, 9-15. http://journals.ukitoraja.ac.id/index.php/agro/article/view/539

Hakim, L. (2015). REMPAH DAN HERBA KEBUN-PEKARANGANRUMAH MASYARAKAT: Keragaman, Sumber Fitofarmaka dan Wisata Kesehatan-kebugaran (1st ed.). Diandra Creative. https://biologi.ub.ac.id/wp-content/uploads/2018/11/E-book-RempahHerba-Luchman-HAkim-2016.pdf 
Manurung, W. K., \& Suminarti, N. E. (2019). Pengaruh Mulsa pada Pertumbuhan dan Hasil Tiga Varietas Stroberi (Fragaria Sp.) Effect of Mulch Application on Growth and Yield of Three Strawberry (Fragaria Sp.). Jurnal Produksi Tanaman, 7(3), 552-558. http://protan.studentjournal.ub.ac.id/index.php/protan/article/view/1088

Manurung, Y. D., Ustriyana, I. N. G., \& Yusuf, R. P. (2015). Analisis Sistem Pemasaran Stroberi Pada Koptan Bali Buyan Berry Di Desa Pancasari Kabupaten Buleleng. EJournal Agribisnis Dan Agrowisata (Journal of Agribusiness and Agritourism), 4(3), 194-202. https://ojs.unud.ac.id/index.php/JAA/article/view/17402

Mappanganro, N. (2013). Pertumbuhan Tanaman Stroberi Pada Berbagai Jenis dan Konsentrasi Pupuk Organik Cair dan Urine Sapi Dengan Sistem Hidroponik Irigasi Tetes. Biogenesis: Jurnal Ilmiah Biologi, 1(2), 123-132. https://doi.org/10.24252/bio.v1i2.458

Megasari, R. (2019). Pengaruh varietas pada berbagai konsentrasi pupuk daun terhadap pertumbuhan dan hasil tanaman stroberi (fragaria sp.). Jurnal Agercolere, 1(2), 4450. https://doi.org/10.37195/jac.v1i2.66

Rofatin, B., Nuryaman, H., \& Suyudi, S. (2016). Optimasi Agroindustri Stroberi. MIMBAR AGRIBISNIS: Jurnal Pemikiran Masyarakat Ilmiah Berwawasan Agribisnis, 1(3), 281290. https://doi.org/10.25157/ma.v1i3.48

Saroinsong, D., Panelewen, V. V. J., Laoh, O. E. H., \& Pakasi, C. B. D. (2012). Agribisnis Tanaman Stroberi Di Desa Rurukan Kecamatan Tomohon Timur. Eugenia, 18(3), 237-242. https://doi.org/10.35791/eug.18.3.2012.4099

Sholihah, A., \& Nurhidayati. (2018). IbM Kelompok Tani Hortikultura Dalam Rangka Perbaikan Manajemen Produksi Kompos. Jurnal Inovasi Hasil Pengabdian Masyarakat (JIPEMAS), 1(2), 94-104. https://doi.org/10.33474/jipemas.v1i2.1513 